\title{
Collagen of the dystrophic hamster diaphragm
}

\author{
N S Al-Zaid, M S Al-Adnani, K A Gumaa
}

\begin{abstract}
The collagen content of the diaphragm was measured in normal and dystrophic hamsters aged 130 and 270 days. The diaphragm collagen content was greater in dystrophic hamsters than in control hamsters of the same age. The effect was greater in the older hamsters whether the collagen content was expressed in terms of the percentage of dry weight, in relation to surface area, or as total collagen. This increase was apparently at the expense of muscle tissue and may be a major factor contributing to respiratory muscle weakness as dystrophy advances.
\end{abstract}

The diaphragm of dystrophic hamsters has been shown to contain substantially increased non-muscle tissue ${ }^{1}$ mostly connective tissue. This was implicated as a cause of muscle weakness, ${ }^{2}$ but the study concerned was relatively qualitative. The present study aimed to quantify the extent of the increase in collagen in the diaphragm of dystrophic hamsters.

\section{N S Al-Zaid}

Department

Department of

Pathology

M S Al-Adnani

Department of

Biochemistry

K A Gumaa

Faculty of Medicine, Safat, Kuwait

Address for reprint requests: Dr N S Al-Zaid,

60 Hanover Gate Mansions

Park Road, London

NW1 4SN

Accepted 11 June.1990

\section{Methods}

Eleven male BIO $F_{1} B$ (control) and 17 male BIO 14.6 (dystrophic) hamsters 130 or 270 days old were obtained from the Bioresearch Institute in Cambridge, Massachusetts. The animals were killed under ether anaesthesia, and the diaphragms removed for wet weight determination. The surface area of intact diaphragm was measured by one observer by flattening the diaphragm over graph paper

Comparison of diaphragms from normal and dystrophic hamsters (means with SD for absolute values and SEM for ratios in parentheses.

\begin{tabular}{lcccc}
\hline & $\begin{array}{l}\text { Age } \\
\text { (days) }\end{array}$ & Normal & Dystrophic & $p$ \\
\hline No of animals & 130 & 6 & 9 & \\
Body weight $(\mathrm{g})$ & 270 & 5 & 8 & \\
& 130 & $138.7(31.3)$ & $101.0(27.0)$ & $<0.05$ \\
Diaphragm & 270 & $143.0(8.7)$ & $107.0(4.8)$ & $<0.001$ \\
Surface area $\left(\mathrm{cm}^{2}\right)$ & 130 & $9.94(3.18)$ & $9.4(2.07)$ & NS \\
& 270 & $10.0(0.24)$ & $8.1(0.57)$ & $<0.001$ \\
Dry weight $(\mathrm{mg})$ & 130 & $59.8(10.58)$ & $45.8(12.30)$ & $<0.05$ \\
& 270 & $69.6(7.42)$ & $61.8(3.70)$ & $=0.05$ \\
Dry wet weight $(\%)$ & 130 & $34.98(1.97)$ & $29.6(1.15)$ & $<0.05$ \\
Collagen & 270 & $29.40(0.82)$ & $25.5(0.31)$ & $<0.001$ \\
mg/diaphragm & 130 & $2.73(0.26)$ & $3.5(0.25)$ & $<0.05$ \\
& 270 & $4.05(0.10)$ & $7.23(0.08)$ & $<0.001$ \\
mg/cm & 130 & $0.27(0.12)$ & $0.37(0.03)$ & $<0.02$ \\
& 270 & $0.41(0.01)$ & $0.90(0.001)$ & $<0.001$ \\
\% of dry weight & 130 & $4.55(0.32)$ & $7.68(0.71)$ & $<0.002$ \\
& 270 & $5.85(0.21)$ & $11.74(0.27)$ & $<0.001$ \\
\hline
\end{tabular}

with $1 \mathrm{~mm}^{2}$ divisions. The diaphragms were then homogenised and dried to constant weight. The collagen content of the diaphragms was determined as their hydroxyproline content. ${ }^{4}$

\section{Results}

Dystrophic hamsters had a significantly lower body weight than age matched control hamsters $(p<0.01)$. The dry weight of the diaphragm and the dry:wet weight ratio was decreased in dystrophic animals of both ages (table). Diaphragmatic surface area was smaller in the dystrophic hamsters at 270 days ( $\mathrm{p}<0.001$ ), but not at 130 days, than in age matched controls (table).

Collagen content, whether expressed in terms of the whole diaphragm or its surface area or as a percentage of the dry weight, was significantly greater in the dystrophic than the control animals at both ages (table).

\section{Discussion}

Both contractility of the diaphragm and ventilatory efficiency have been shown to decline in dystrophic hamsters by comparison with normal hamsters. ${ }^{12}$ This decline, which was accentuated by aging, was attributed to several factors, including tissue hydration as indicated by the decrease in dry:wet weight ratio reported in our data.

In normal rat muscle the increase in collagen between 3 weeks and 2 years of age is no more than $53 \%$ and correlates closely with muscle stiffness as indicated by passive length-tension measurements. ${ }^{3}$ The increase in diaphragm collagen between 130 and 270 days in the normal hamsters was $28 \%$, compared with $53 \%$ in the dystrophic hamsters. When dystrophic and normal hamsters of the same age are compared, collagen concentration was twice as high in the dystrophic animals at 270 days as in the control hamsters, and about $70 \%$ greater at 130 days. The high collagen deposition may be reflected in the performance of the diaphragm, especially during expiratory manoeuvres.

These results imply that increased collagen synthesis could be a continuous process and that both remodelling and removal of connective tissue, as observed in wound healing, ${ }^{56}$ may fail to occur in chronic conditions such as progressive dystrophy. A pattern similar to that of wound healing has been observed in acute, post-traumatic pulmonary fibrosis, ${ }^{7}$ implying that in chronic pulmonary fibrosis ${ }^{89}$ the problem may be the inability to remove or remodel (or both) the newly synthesised collagen. Whether the hypothesis proposed for chronic pulmonary fibrosis can be extended to 
include fibrosis in other organs or other diseases, such as the diaphragm of the dystrophic hamsters, is unknown, though it seems an attractive idea in view of the data presented in this report.

We conclude that impairment of ventilatory efficiency and contractility of the diaphragm in dystrophic hamsters could be due to increased deposition of collagen.

1 Burbach JA, Schlenker EH, Johnson JL. Morphometry, histochemistry and contractility of dystrophic hamster diaphragm. Am J Physiol 1987;22:272-84.

2 Schlenker EH. An evaluation of ventilation in dystrophic Syrian hamsters. J Appl Physiol 1984;56:914-21.
3 Al-Naqueeb MA, Al-Zaid NS, Goldspink G. Connective tissue changes and physical properties of developing and aging skeletal muscle. $J$ Anat 1984;139:677-89.

4 Grant RA. Estimation of hydroxyproline by the autoanalyser. J Clin Pathol 1964;17:685-7.

5 Zeitz M, Ruis-Torres A, Merker HJ. Collagen metabolism in granulating wounds of rat skin. Arch Dermatol Res 1978;263:207-14

6 Hering TM, Marchant RE, Anderson JM. Type V collagen during granulation tissue development. Exp Mol Pathol 1983;39:219-29.

7 Nerlich AG, Nerlich ML, Müller PK. Pattern of collagen types and molecular structure of collagen in acute posttraumatic pulmonary fibrosis. Thorax 1987;42:863-9.

8 Takiya C, Peyrol S, Cordier JF, Grimaud JA. Connective tissue organisation in human pulmonary fibrosis. Virch Arch Cell Pathol 1983;44B:223-40.

9 Laurent GJ. Lung collagen: more than scaffolding. Thorax 1986;41:418-28. 